\title{
Nidicolous beetle species richness is driven by Barn Owl's nests occupancy and landscape structure
}

\author{
Vivien Cosandey ${ }^{1}\left[\right.$ Robin Séchaud $^{1} \cdot$ Paul Béziers $^{1,3} \cdot$ Yannick Chittaro $^{2} \cdot$ Andreas Sanchez $^{2} \cdot$ Alexandre Roulin $^{1}$
}

Received: 14 October 2020 / Revised: 6 February 2021 / Accepted: 25 February 2021 / Published online: 9 March 2021

(c) The Author(s) 2021

\begin{abstract}
Bird nests are specialized habitats because of their particular composition including nest detritus and bird droppings. In consequence, they attract a specialized arthropod community considered as nidicolous, which includes species only found in bird nests (strictly nidicolous) or sometimes found in bird nests (facultatively nidicolous). Because the factors influencing the entomofauna in bird nests are poorly understood, in autumn 2019, we collected nest material in 86 Barn Owl (Tyto $a l b a$ ) nest boxes. We investigated whether the invertebrate species richness was related to Barn Owl nest box occupancy, the density of available nest boxes and the landscape structure. We found 3,321 nidicolous beetle specimens belonging to 24 species. Species richness of strictly nidicolous beetles was 2.7 times higher in nest boxes occupied by a family of Barn Owls the previous spring compared to unoccupied nest boxes. It was also higher in sites that were more often occupied by Barn Owls in the five previous years and in areas surrounded by a higher proportion of crop fields. For facultatively nidicolous beetles, the density of Barn Owl nest boxes enhanced the species richness. In conclusion, our study suggests that the strictly nidicolous beetles benefit from occupied nest boxes of Barn Owls, whereas facultatively nidicolous beetles look for nest boxes independently of whether Barn Owls occupy them. Our study highlights the importance of bird nests for a suite of invertebrates.
\end{abstract}

Keywords Nidicolous beetles $\cdot$ Species richness $\cdot$ Tyto alba $\cdot$ Patchy habitat $\cdot$ Landscape structure $\cdot$ Nest box

\section{Zusammenfassung}

Der Artenreichtum von Käfern in Schleiereulennestern wird durch die Belegung der Nester und die Landschaftsstruktur bestimmt.

Vogelnester sind durch ihre besondere Zusammensetzung mit Nestdetritus und Vogelkot ganz spezielle Lebensräume. Infolgedessen ziehen sie eine ganz besondere Gruppe von Arthropoden an, sog. nidikole Arten, die nur in Vogelnestern (strikt nidikol) oder manchmal in Vogelnestern (fakultativ nidikol) vorkommen. Da die Faktoren, die die Entomofauna in Vogelnestern beeinflussen, bislang nur unzureichend erforscht sind, haben wir im Herbst 2019 Nestmaterial aus 86 Nistkästen der Schleiereule (Tyto alba) gesammelt. Wir untersuchten, ob der Artenreichtum an Wirbellosen mit der Belegung von Schleiereulen-Nistkästen, der Dichte der verfügbaren Nistkästen und der Landschaftsstruktur zusammenhängt und fanden 24 Arten nidikoler Käfer mit insgesamt 3.321 Einzeltieren. Der Artenreichtum an strikt nidikolen Käfern war in Nistkästen, die im vorangegangenen Frühjahr von einer Schleiereulenfamilie besetzt waren, 2,7-mal höher als in unbesetzten

Communicated by T. Gottschalk.

Vivien Cosandey

vivien.cosandey@unil.ch

1 Department of Ecology and Evolution, University of Lausanne, Lausanne, Switzerland

2 info fauna-CSCF, Avenue Bellevaux 51, Neuchâtel, Switzerland

3 Faculty of Agricultural and Environmental Sciences, McGill University, Montreal, Canada 
Nistkästen. Es gab außerdem einen größeren Artenreichtum an Standorten, die in den fünf vorangegangenen Jahren häufiger von Schleiereulen besetzt waren, und in Gebieten mit einem höheren Anteil an Getreidefeldern. Bei fakultativ nidikolen Käfern erhöhte die Dichte der Schleiereulennistkästen den Artenreichtum der Käfer. Zusammenfassend deutet unsere Studie darauf hin, dass strikt nidikole Käfer von besetzten Nistkästen der Schleiereulen profitieren, während fakultativ nidikole Käfer nach Nistkästen suchen unabhängig davon, ob diese von Schleiereulen besetzt sind oder nicht. Unsere Studie unterstreicht die Bedeutung von Vogelnestern für eine Reihe von Wirbellosen.

\section{Introduction}

The presence of a species in a given locality depends on many factors including its adaptation to the prevailing local conditions and interspecific interactions (Hutchinson 1957), dispersal capacity (MacArthur and Wilson 2001) and connectivity between suitable habitats (Taylor et al. 1993). Studying patchy habitats provides an appropriate system to identify the factors that influence species assemblages. Patchy habitats being distributed as single units in the landscape, they are suited to characterize the organismic community, which has colonized it (Finn and Giller 2000; Hanski 2016).

In non-colonial birds, nests are patchily distributed and highly specialized ecological niches that contain decaying matters originating from construction materials, uneaten food items, droppings and bird cadavers. The invertebrates that colonize nests are strictly or facultatively nidicolous depending on whether they rely on bird nests for all, or part, of their life cycle. These nidicolous animals include detritivorous species (feeding on decaying organic matter), necrophorous (feeding on corpses or carrion) and carnivorous (predating on other invertebrates like fly larvae) (Nordberg 1936). Although the faunistic composition of the nidicolous arthropods associated with nests of passerines (Jurík and Šustek 1978; Krištofík et al. 1994; Šustek and Krištofík 2003) and raptors (Dražina and Špoljar 2009; Hågvar 1975; Krištofík et al. 2003) have been described in a few instances, the factors influencing their species richness are still poorly understood. Nest-related factors can affect nidicolous fauna as shown in the Eurasian hoopoe (Upupa epops), where nest dryness reduces the number of carnivorous beetle species by limiting the development of their prey such as flies, mites and fleas (Krištofík et al. 2013). The presence of birds also has an influence, as shown in the Eurasian penduline tit (Remiz pendulinus), with nidicolous arthropods being present in occupied nests (Krištofík et al. 1995).

The invertebrate species specialized in exploiting patchy resources like bird nests are prone to local extinction because nests are not self-sustainable resources (Beaver 1977). The distance between suitable habitats (i.e. nest density) could facilitate dispersal of the nidicolous fauna, and hence positively affect species richness. Beetles, which represent a significant part of the nidicolous arthropods both in terms of species number and abundance, are represented by carnivorous, detrivorous and necrophorous species (Dražina and Špoljar 2009; Jurík and Šustek 1978), have a strict or facultative nidicolous ecology and are found the whole year in nests even if they are short-lived (Šustek and Hornychová 1983). In the present study, we monitored the beetle fauna found in nest boxes specifically built for Barn Owls (Tyto $a l b a$ ) and studied its species richness in relation to temporal and spatial factors, such as nest box occupancy by owls and surrounding landscape structure. We predict that a high abundance of crop fields decreases the species richness of nidicolous insects like in Germany where the arthropod species richness found in grasslands and forests were negatively affected by intensive agricultural practices (Seibold et al. 2019). We also investigated the impact of the density of raptor nest boxes as they could act as a beetle reservoir facilitating the dispersal of beetles inside the study area. Similarly, nest boxes that are more often occupied by Barn Owls could be a reservoir of nidicolous insects, particularly of the strictly nidicolous beetles. Finally, we wanted to bring additional arguments in favour of the nest boxes, installed in agricultural landscapes to provide nesting sites for raptors, which are efficient pest controller (Askew et al. 2007), by illustrating their benefits for other organism, such as nidicolous beetles.

\section{Material and methods}

\section{Study area}

The study was conducted on the western Swiss Plateau in an area of approximately $1,000 \mathrm{~km}^{2}$ between Lausanne and Avenches at an altitude comprised between 420 and $710 \mathrm{~m}$ (Fig. 1). Intensive agriculture dominates the landscape with the crop being the most frequently cultivated plant, but there are small areas of forests and towns (Frey et al. 2011). In the study area, 400 artificial Barn Owl nest boxes were installed in farms and barns. Common Kestrels (Falco tinnunculus) sometimes also use these boxes to breed. As these Barn Owl nest boxes have been monitored since 1990, we have precise data concerning their occupancy. Unlike many other birds, Barn Owls do not clean their nest, which accumulates remains of food, droppings and pellets. 


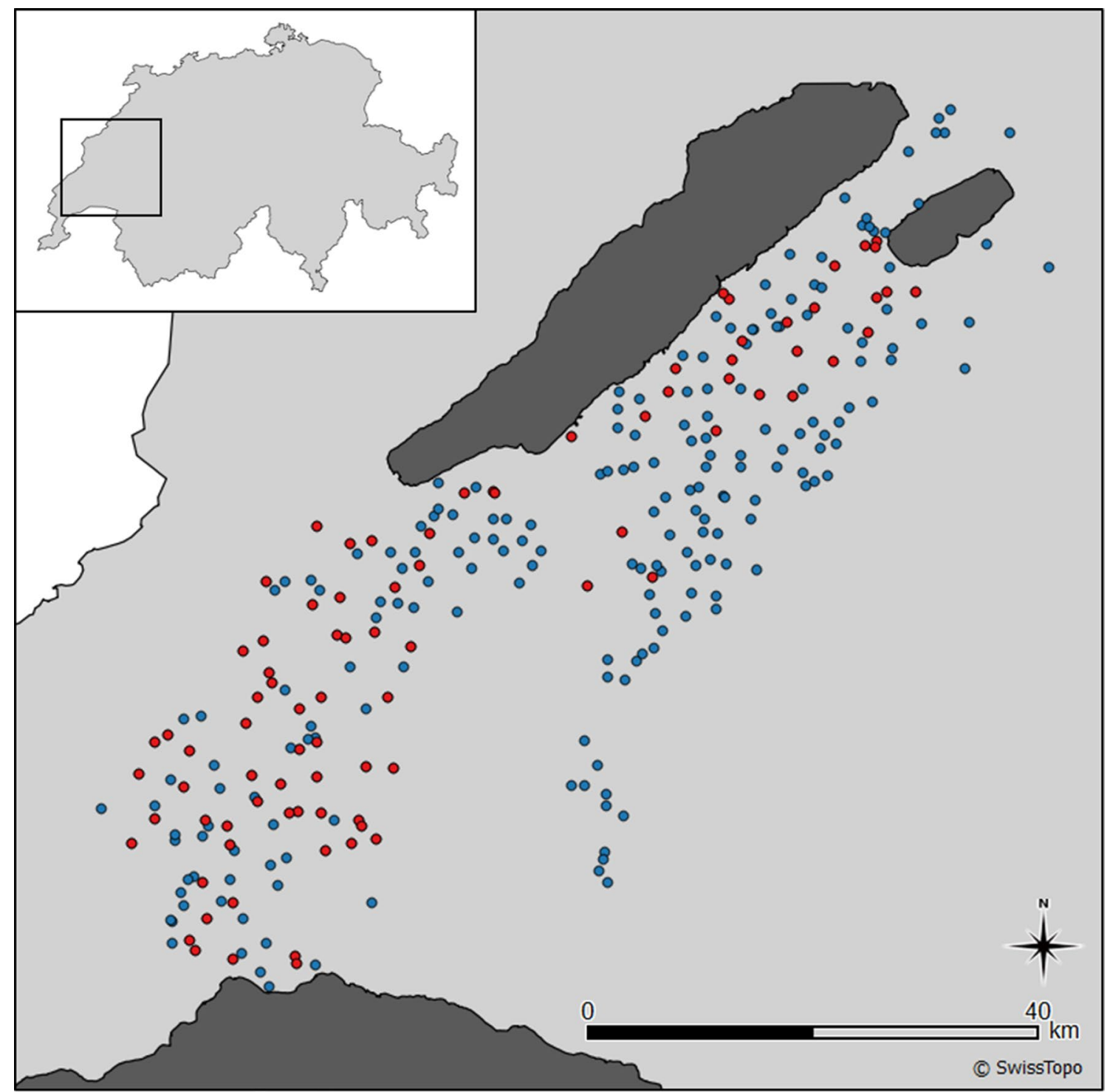

Fig. 1 Barn Owl nest boxes in the study area. Red dots represent the nest boxes that were sampled

\section{Sampling}

To minimize disturbance, we visited Barn Owl nests after the breeding season. From the 20th of September to the 3rd of October 2019, we sampled 86 independent nest boxes (i.e. in 86 different farms), of which half were occupied by a Barn Owl family in 2019 (the other half was not occupied by any bird). To test whether the entomofauna is positively influenced by the number of times a nest box has been occupied by a Barn Owl family, we calculated the percentage of years each of the 86 nest boxes was occupied during the last five years (2015-2019). In each of them, we sampled homogeneously across the substrate surface six liters of the litter using a little shovel. This quantity was determined as optimal to record the maximal number of beetle species (see Figure S1).

We left the nest box substrates on sieves (gauge size $0.5 \mathrm{~cm}) 2$ days, giving ample time to capture all living arthropods. After this period, we manually sorted all dead arthropods remaining in the substrate samples. Using a binocular, we identified insects with morphological criteria found in the specialized literature (Freude et al. 1999, 2011; Gerstmeier 1998; Kadej et al. 2007; Klausnitzer 2011; Novák 2014; Vienna 1980; Zahradník 2013). All the specimens (or fragments) of arthropods were counted and recorded as alive (adult or larvae) or dead. The species were classified as strictly or facultatively nidicolous, or as prey (i.e. brought by Common Kestrels or by Barn Owls), accidental nest box visitors or avian parasites (Table S3) 
according to their ecology (Koch 1989a, b, and references therein) and considering if they were found alive (more likely to be nidicolous) or dead (more likely to be a prey item). We also reported the trophic guilds of each species, i.e. carnivorous, detritivorous (i.e. consume dead organic matters from diverse origins) or necrophorous (i.e. consume dead animals).

For the statistical analyses, we only considered the nidicolous beetles found alive (as adults or larvae), since some of the dead ones may have been there for several years. We also observed many Anthrenus sp. and Attagenus sp. larvae that are difficult to identify to the species level. This is why we included all the specimens of these taxa (even adults) in the analyses with identification to the genus level.

\section{Landscape structure}

We recorded landscape structure in a 1,000 m radius around each nest box (we obtained qualitatively similar results if considering radii of 500 or $1,500 \mathrm{~m}$, see Table S2) within which we extracted the proportion of crop fields from the land-use data obtained from the "Service de l'Agriculture et de la Viticulture du canton de Vaud" and the "Service de l'Agriculture du canton de Fribourg". We calculated the density of nest boxes as the number of Barn Owl and Common Kestrel nest boxes within the radius (part of the nest boxes were specifically designed for Barn Owls and others for kestrels).

\section{Data analyses}

We ran four generalized linear models (GLM) to investigate the effect of Barn Owl nest box occupancy and the landscape structure around each nest box on nidicolous beetle species richness. The number of nidicolous beetle species (strictly or facultatively nidicolous species in separate models) was the response variable. We included whether the box was occupied by a Barn Owl family in 2019 (the year when beetles were collected) and the occupancy rate over the five past years (2015-2019) in separate models because these two variables were correlated $\left(r^{2}=0.35, n=86, P=0.001\right)$. In each of these two models, we included two other explanatory variables defining the landscape structure in a $1,000 \mathrm{~m}$ radius around each nest box, i.e. the proportion of crop fields and the density of nest boxes.

We used a quasi-Poisson distribution for the models including the strictly nidicolous species because the residuals were overdispersed [for both models: dispersion $>1.10$, $P>0.05$, dispersion test function of the AER package (Kleiber and Zeileis 2008)] and a Poisson distribution for the models including the facultative nidicolous species as the residuals were not overdispersed (for both models: overdispersion $<1, P<0.5$ ). All the statistical analyses were performed with R Studio version 1.0.153. (R core team 2017) and the package lme4 (Bates et al. 2015).

\section{Results}

\section{Nidicolous arthropods inventory}

We found a total of 3,689 arthropods belonging to 84 species of which 3,493 were beetles (dead or alive) belonging to 72 species (Table S3). Although only 24 of these 72 beetle species had a nidicolous ecology, they were the most frequent: 2,199 individuals belonging to five species of strictly nidicolous beetles and 1,122 individuals of 19 species of facultatively nidicolous beetles. Among these 24 nidicolous species, 4 were carnivorous, 9 detritivorous and 11 necrophorous (Table S1, Figure S4). Thirty species (137 individuals) were prey, 13 species (30 individuals) accidental visitors (Table S3), and 5 species (5 individuals) could not be classified as prey or accidental/unexpected visitors.

\section{Species richness of strictly nidicolous beetles}

The species richness of the strictly nidicolous beetle species was higher in nest boxes used (mean \pm SE: $1.48 \pm 0.18$ species, $P=0.0009)$ than unused $(0.54 \pm 0.21$ species) by Barn Owls in 2019 (Table 1; Fig. 2a, c). Species richness was also
Table 1 The number of strictly nidicolous beetle species in relation to the landscape structure and occupancy of nest boxes by Barn Owls

\begin{tabular}{|c|c|c|c|c|c|c|}
\hline \multirow[b]{2}{*}{ Predictors } & \multicolumn{3}{|c|}{ Occupancy 2019} & \multicolumn{3}{|c|}{ Occupancy rate (2015-2019) } \\
\hline & Estimate $\pm \mathrm{SE}$ & $t$ value & $p$ value & Estimate $\pm \mathrm{SE}$ & $t$ value & $p$ value \\
\hline Intercept & $-0.38 \pm 0.21$ & -1.82 & 0.07 & $0.09 \pm 0.12$ & 0.75 & 0.445 \\
\hline Nest occupancy & $0.84 \pm 0.24$ & 3.45 & 0.0009 & $0.34 \pm 0.12$ & 2.82 & 0.006 \\
\hline Crop fields & $0.35 \pm 0.12$ & 3.00 & 0.004 & $0.32 \pm 0.12$ & 2.64 & 0.01 \\
\hline Nest box density & $0.09 \pm 0.12$ & 0.77 & 0.45 & $0.0004 \pm 0.12$ & 0.003 & 0.99 \\
\hline
\end{tabular}

Results from two generalized linear models on species number in 86 Barn Owl nest boxes. The influence of Barn Owl occupancy in 2019 and mean occupancy over five years (2015-2019) are presented in relation to the proportion of crop fields around the nest boxes and the density of Barn Owl and Common Kestrel nest boxes. Statistically significant variables are highlighted in bold. The degree of freedom of all our variables was 85 
Fig. 2 Relationship between nest box occupancy by Barn Owls and species richness of strictly nidicolous beetles (a, c) and facultatively nidicolous beetles $(\mathbf{b}, \mathbf{d})$. We considered two types of nest box occupancy: during the year of the beetle collection (2019) (a, b) and the five previous years (2015-2019) (c, d). The statistical significances are reported on the graphs. The error bars $(\mathbf{a}, \mathbf{b})$ and the grey area $(\mathbf{c}, \mathbf{d})$ correspond to the CI $95 \%$
Strictly nidicolous beetles

Facultatively nidicolous beetles

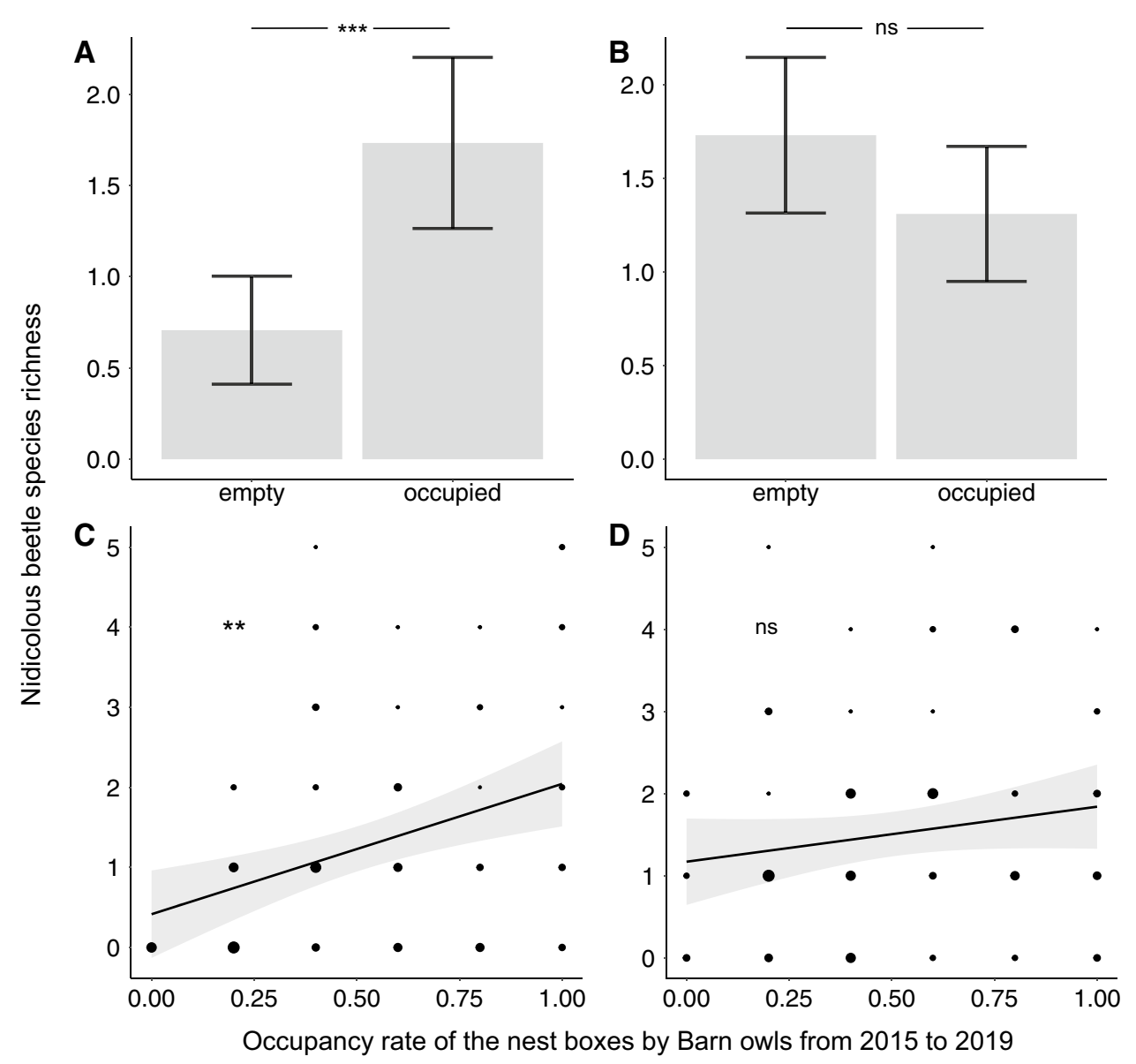

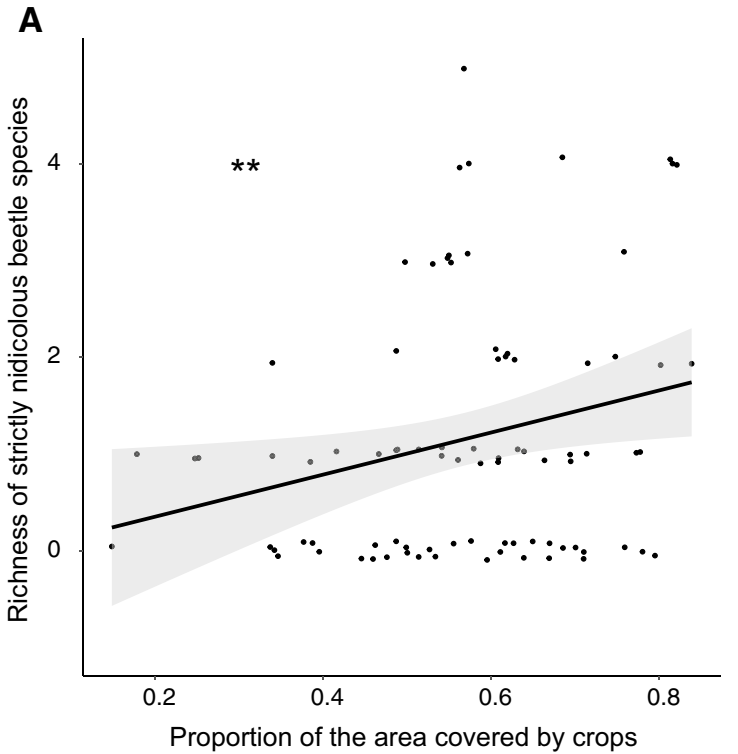

Fig. 3 Relationship between the proportion of the environment that is covered by crop fields and the species richness of strictly nidicolous beetles (a) and the relationship between the number of nest boxes specifically dedicated to Barn Owls and Common Kestrels on the spe-

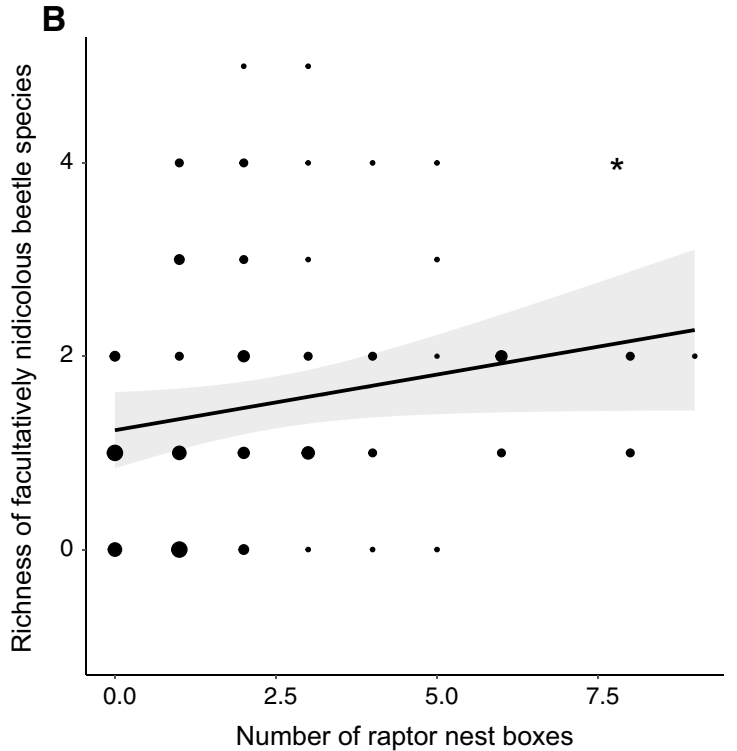

cies richness of facultatively nidicolous beetles (b). The statistical significances are reported on the graphs. The grey areas correspond to the $95 \% \mathrm{CI}$ 
higher in nest boxes that Barn Owls more often used during the five previous years (2015-2019) and in boxes surrounded by more crop fields (Table 1; Fig. 3a). The density of Barn Owl and Common Kestrel nest boxes was not associated with species richness (Table 1).

\section{Species richness of facultatively nidicolous beetles}

The species richness of facultatively nidicolous beetles was neither influenced by whether Barn Owls occupied nest boxes in $2019(1.51 \pm 0.14$ species per nest box, $P=0.08)$ nor by the occupancy rate of nest boxes over the past five years and the number of crop fields (Table 2; Fig. 2b, c). On the other hand, species richness was higher in areas where the density of Barn Owl and Common Kestrel nest boxes was higher (Table 2).

\section{Discussion}

We investigated the influence of Barn Owl nest occupancy and landscape structure on the nidicolous beetle species richness found inside nest boxes. Sites occupied by Barn Owls during the year of sampling were colonized by a higher number of strictly nidicolous beetle species compared to unoccupied nest boxes. The recent occupation of a nest box by a Barn Owl breeding pair leads to an accumulation of pellets, prey cadavers and droppings on which fly larvae develop. Since most of the strictly nidicolous beetles are carnivorous (Table S1) preying on fly larvae (Šustek and Krištofík 2002, 2003), they benefit indirectly from the presence of birds. We also found a higher number of strictly nidicolous beetle species in nest boxes more often occupied by Barn Owls over the past 5 years (2015-2019) (Table 1; Fig. 2c) suggesting successive colonization events or the production of multiple generations over the years. By repeatedly occupying the same nest box, Barn Owls favour the presence of strictly nidicolous beetles. In contrast, the facultatively nidicolous beetles did not benefit from the recent presence of Barn Owls (Table 2; Fig. 2b, c) probably because most of these beetles are necrophorous or detritivorous and can thus still find food several years after the use of a nest box by a Barn Owl family.

The lack of connectivity between habitats in agricultural landscapes is a significant threat to biodiversity (Kishbaugh and Yocom 2000; Kruess and Tscharntke 1994). The forest dung and carrion beetles, two distinct ecological groups of species which use patchy resources such as nidicolous beetles, show a reduced species richness in fragmented woods (Klein 1989). Surprisingly, we found that the strictly nidicolous beetle richness was positively related to the proportion of the environment covered by crop fields (Table 1; Fig. 3a). This result could suggest that these beetles have great dispersal capacities and concentrate in a few suitable habitats such as Barn Owl nest boxes. Moreover, the strictly nidicolous beetle species richness was not related to the density of nest boxes probably because these beetles do not colonize unoccupied nest boxes, which was the case of a significant proportion of these nest boxes. In contrast, we found that the proportion of crop fields was not related to the richness of facultatively nidicolous beetle species (Table 2) but that the density of nest boxes positively influenced it (Table 2; Fig. 3b). This suggests that the facultatively nidicolous beetles can benefit from the density of nest boxes since they do not require the presence of birds to proliferate. The nest boxes do not only facilitate cavity-nesting birds but apparently could also serve as a corridor through more intensively farmed areas for invertebrate species that rely on cavity-nesting birds or diverse decaying materials.

The presence of a diverse nidicolous entomofauna is most of the time beneficial for birds as the necrophorous and detritivorous nidicolous fauna helps to keep the nests clean by consuming its rotting substrate. This indirect interaction between birds and invertebrates was qualified as facultative mutualism by Balgooyen (1976). Furthermore, Sustek and Jurik (1980) showed the critical role of a carnivorous beetle species, Microglotta nidicola, in the
Table 2 Number of facultatively nidicolous beetle species in relation to the occupancy of nest boxes by Barn Owls and to landscape structure

\begin{tabular}{lcccccccc}
\hline Predictors & \multicolumn{2}{l}{ Occupancy 2019} & & & \multicolumn{3}{l}{ Occupancy rate $(2015-2019)$} \\
\cline { 2 - 3 } & Estimate \pm SE & $t$ value & $p$ value & & Estimate \pm SE & $t$ value & $p$ value \\
\hline Intercept & $0.53 \pm 0.12$ & 4.46 & $<0.0001$ & & $0.38 \pm 0.09$ & 4.24 & $<0.00001$ \\
Nest occupancy & $-0.31 \pm 0.18$ & -1.75 & 0.08 & & $0.05 \pm 0.95$ & 0.54 & 0.59 \\
Crop fields & $0.08 \pm 0.09$ & 0.88 & 0.38 & & $0.06 \pm 0.09$ & 0.69 & 0.49 \\
Nest box density & $\mathbf{0 . 2 3} \pm \mathbf{0 . 0 9}$ & $\mathbf{2 . 6 3}$ & $\mathbf{0 . 0 0 8}$ & & $\mathbf{0 . 2 1} \pm \mathbf{0 . 1 0}$ & $\mathbf{2 . 1 8}$ & $\mathbf{0 . 0 3}$ \\
\hline
\end{tabular}

Results from two generalized linear models on the number of beetle species found in 86 Barn Owl nest boxes. The relationship with the Barn Owl occupancy in 2019 and the mean occupancy during the last five years (2015-2019) are presented in relation to the proportion of crop fields in a 1,000 $\mathrm{m}$ radius around the nest boxes as well as the number of nest boxes dedicated explicitly to the reproduction of Barn Owls and Common Kestrels. Statistically significant variables are highlighted in bold. The degree of freedom of all our variables was 85 
control of the number of fleas in the nests of the Sand Martin (Riparia riparia). However, the outbreak of necrophorous beetles can be detrimental by eating nestlings alive (Snyder et al. 1984) although such behaviour has never been reported in the Barn Owl. To keep a high species richness of arthropods, the conservation of multiple bird species is crucial, since some nidicolous beetles maybe specialized by colonizing the nests of some specific bird species (Hågvar 1975).

Our study provided new data on the distribution of some beetles, particularly strictly nidicolous species that were previously only rarely reported in Switzerland. We found Gnathoncus communis, which frequently feeds on raptor rejection pellets (Secq 1985), in 38 localities although it was previously reported only 13 times in Switzerland (Sanchez and Chittaro 2018). In addition, the total number of localities with Dermestes bicolor and Saprinus subnitescens were, respectively, multiplied by 2.75 and 1.66 thanks to our study (Swiss database info fauna-CSCF). This suggests that these species are more common than previously thought. Artificial nest boxes probably provide important substitution habitat for these species. Therefore, by installing nest boxes, ornithologists favour birds and a high diversity of nidicolous arthropod fauna.

Our study provides an example of the interactions between birds and their associated nidicolous fauna. Further studies should be performed to determine if there is an influence of microclimatic factors inside nest boxes on the nidicolous beetle species richness and compare the fauna associated with different raptor species nests.

Supplementary Information The online version contains supplementary material available at https://doi.org/10.1007/s10336-021-01875-z.

Acknowledgements We thank the people who helped us in the field: Kim Schalcher, Ana Paula Machado, Tatiana Zingre and Nicolas Rausa. The following persons participated in arthropod identification: Christoph Germann (Coleoptera, Curculionidae and Chrysomelidae), Henryk Luka (Coleoptera, Staphylinidae), Bastien Guibert (Heteroptera, Lygaeidae), Rudolf Bryner (Lepidoptera, Tineidae) and Christophe Praz (Hymenoptera, Apidae). We also acknowledge Michel Sartori (Musée cantonal de zoologie, Lausanne) for providing us with the photographic equipment.

Author contributions VC, RS, PB conceived the study, VC, YC, AS identified insects, VC, RS and $\mathrm{PB}$ performed the statistical analyses, $\mathrm{VC}, \mathrm{AR}$ wrote the paper with the help of RS, PB, YC, AS.

Funding Open Access funding provided by Université de Lausanne. The study was supported by the Swiss National Science Foundation (Grant n 31003A_173178).

\section{Declarations}

Conflict of interest The authors declare that they have no competing interest.

Availability of data and material Available from the first author.
Open Access This article is licensed under a Creative Commons Attribution 4.0 International License, which permits use, sharing, adaptation, distribution and reproduction in any medium or format, as long as you give appropriate credit to the original author(s) and the source, provide a link to the Creative Commons licence, and indicate if changes were made. The images or other third party material in this article are included in the article's Creative Commons licence, unless indicated otherwise in a credit line to the material. If material is not included in the article's Creative Commons licence and your intended use is not permitted by statutory regulation or exceeds the permitted use, you will need to obtain permission directly from the copyright holder. To view a copy of this licence, visit http://creativecommons.org/licenses/by/4.0/.

\section{References}

Askew NP, Searle JB, Moore NP (2007) Agri-environment schemes and foraging of barn owls Tyto alba. Agric Ecosyst Environ 118:109-114

Balgooyen TG (1976) Behavior and ecology of the American kestrel (Falco sparverius L.) in the Sierra Nevada of California University of California publications in zoology, vol 103. University of California Press, Berkeley

Bates D, Mächler M, Bolker B, Walker S (2015) Fitting Linear Mixed-Effects Models Using lme4. J Stat Soft 67:1-48

Beaver RA (1977) Non-equilibrium "island" communities: diptera breeding in dead snails. J Anim Ecol 46:783

Dražina T, Špoljar M (2009) Insect fauna in nests of the Eurasian griffon vulture (Gyps fulvus) in Croatia. Biologia 64:969-973

Finn JA, Giller PS (2000) Patch size and colonization patterns: an experimental analysis using north temperate coprophagous dung beetles. Ecography 23:315-327

Freude H, Harde KW, Lohse GA, Lucht WH (1999) Die Käfer Mitteleuropas. Band 6. Diversicornia (Lyctidae-Byrrhidae). Goecke \& Evers, Krefeld

Freude H, Harde KW, Lohse GA (2011) Die Käfer Mitteleuropas 5. Staphylinidae II. Goecke \& Evers, Krefeld

Frey C, Sonnay C, Dreiss A, Roulin A (2011) Habitat, breeding performance, diet and individual age in Swiss Barn owls (Tyto alba). J Ornithol 152:279-290

Gerstmeier R (1998) Checkered beetles. Illustrated key to the Cleridae of the western Palaearctic. Margraf, Weikersheim

Hågvar S (1975) Coleoptera in nests of birds of prey. Norwegian J Entomoly 22:135-141

Hanski I (2016) Dung beetle ecology. Princeton University Press, Princeton

Hutchinson GE (1957) Concluding remarks. Cold Spring Harb Symp Quant Biol 22:415-427

Jurík M, Šustek Z (1978) The Coleoptera of Passer domesticus in Czechoslovakia. Věst Česk Spol Zool 42:255-272

Kadej M, Háva J, Kalík V (2007) Review of the Anthrenus pimpinellae species group from Palaearctic region (Coleoptera: Dermestidae: Anthrenini). Genus 18:721-750

Kishbaugh MA, Yocom DH (2000) The impact of habitat fragmentation on arthropod biodiversity: an experimental study. Am Biol Teach 62:8

Klausnitzer B (2011) Die Käfer Mitteleuropas 3 Adephaga II, Palpicornia. Goecke \& Evers, Krefeld

Kleiber C, Zeileis A (2008) Applied econometrics with R. Springer, New York

Klein BC (1989) Effects of forest fragmentation on dung and carrion beetle communities in Central Amazonia. Ecology 70:1715-1725

Koch K (1989a) Die Käfer Mitteleuropas, Ökologie 1. Goecke \& Evers, Krefeld 
Koch K (1989b) Die Käfer Mitteleuropas, Ökologie 2. Goecke \& Evers, Krefeld

Krištofík J, Mašán P, Šustek Z, Kloubec B (2003) Artropods (Pseudoscorpionida, Acari, Coleoptera, Siphonaptera) in nests of the Tengmalm's owl, Aegolius funereus. Biologia 58:231-240

Krištofík J, Mašán P, Šustek Z, Nuhličková S (2013) Arthropods (Acarina, Coleoptera, Siphonaptera) in nests of hoopoe (Upupa epops) in Central Europe. Biologia 68:155-161

Krištofík J, Šustek Z, Gadjoš P (1995) Arthropods in the penduline tit (Remiz pendulinus) nests: occurence and abundance in different breeding phases. Biologia 50:487-493

Krištofík J, Sustek Z, Gadjoš P (1994) Arthropods in nests of the Sand martin (Riparia riparia Linnaeus, 1758) in South Slovakia. Biologia 49:683-690

Kruess A, Tscharntke T (1994) Habitat fragmentation, species loss, and biological control. Science 264:1581-1584

MacArthur RH, Wilson EO (2001) The theory of island biogeography. Princeton University Press, Princeton

Nordberg S (1936) Biologisch-Ökologische Untersuchungen über die Vogelnidicolen. Acta Zool Fenn 21:1-168

Novák V (2014) Beetles of the family Tenebrionidae of Central Europe. Zoological keys, Academia, Prague

Sanchez A, Chittaro Y (2018) Liste commentée des Histeridae et Sphaeritidae de Suisse (Coleoptera, Histeroidea). Entomol Bl Coleopt 114:335-352

Secq M (1985) A propos de la présence de Gnathoncus schmidti Reitter en Dordogne (Coleoptera Histeridae). L'Entomologiste 41:69-72

Seibold S, Gossner MM, Simons NK, Blüthgen N, Müller J, Ambarlı D, Ammer C, Bauhus J, Fischer M, Habel JC, Linsenmair KE, Nauss T, Penone C, Prati D, Schall P, Schulze E-D, Vogt J, Wöllauer S, Weisser WW (2019) Arthropod decline in grasslands and forests is associated with landscape-level drivers. Nature 574:671-674

Snyder NFR, Ogden JC, Bittner JD, Grau GA (1984) Larval Dermestid beetles feeding on nestling Snail kites, Wood storks, and Great blue herons. Condor 86:170

Šustek Z, Hornychová D (1983) The beetles (Coleoptera) in the nests of Delichon urbica in Slovakia. Acta rerum naturalium Musei nacionalis Slovakiae, Bratislava 29:119-134

Šustek Z, Jurík M (1980) The coleoptera from nests of Riparia riparia in Czechoslovakia. Czechoslovak Entomological Society 44:286-292

Šustek Z, Krištofík J (2002) Beetles (Coleoptera) in deserted nests of Phoenicurus ochruros, Parus caerulens, Parus major, Sitta europaea and Sturnus vulgaris. Entomofauna Carpathica 14:64-69

Šustek Z, Krištofík J (2003) Beetles (Coleoptera) in nests of house and tree sparrows (Passer domesticus and P. montanus). Biologia 58:953-965

Taylor PD, Fahrig L, Henein K, Merriam G (1993) Connectivity is a vital element of landscape structure. Oikos 68:571

Ugland KI, Gray JS, Ellingsen KE (2003) The species-accumulation curve and estimation of species richness. J Anim Ecol 72:888-897

Vienna P (1980) Coleoptera: Histeridae. Fauna d'Italia, Calderini, Bologna

Zahradník P (2013) Beetles of the family Ptinidae of Central Europe. Zoological keys. Academia, Prague

Publisher's Note Springer Nature remains neutral with regard to jurisdictional claims in published maps and institutional affiliations. 